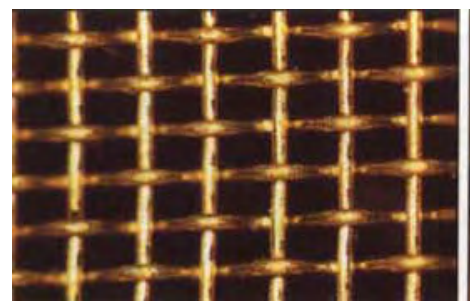

Woven brass screen with a regular weave.

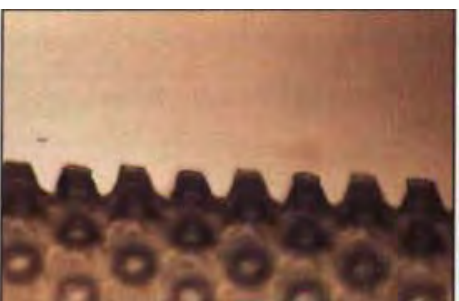

High-density polyethylene sheet, male surface.

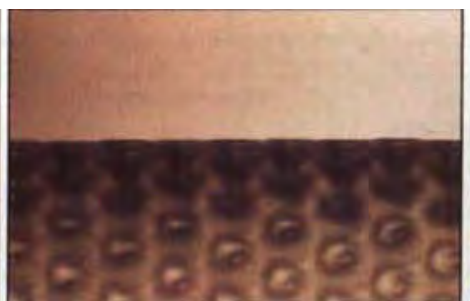

High-density polyethylene sheet, female surface.

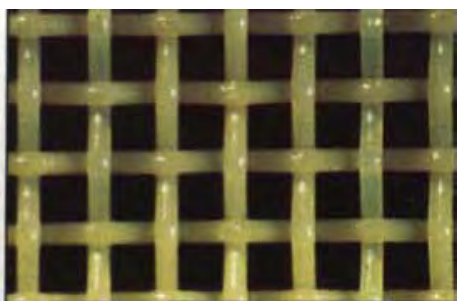

High-density polyethylene fiber screen.

\title{
Screens deny specific pests entry to greenhouses
}

\author{
James A. Bethke $\square$ Richard A. Redak $\square$ Timothy D. Paine
}

\section{Screens can exclude certain pests from greenhouses and therefore reduce the need for pesticides on greenhouse crops. They can per- haps also be used to create a small production area for biologi- cal control organisms within the greenhouse. When selecting a screen for either use, the pore size in the material is an important factor.}

Leaf miners, whiteflies, aphids and thrips are the major insect pests in greenhouse crops. They cause physical and aesthetic damage, and thrips and aphids may also transmit organisms that cause plant diseases. Because many pests have developed or are rapidly developing resistance to the currently available insecticides and a number of effective compounds are becoming unavailable because of health, safety and environmental concerns (see California Agriculture JulyAugust 1990), insect pest control strategies are shifting toward nonchemical alternatives. To control greenhouse pests, growers are using predators and parasitoids, insect-resistant plant material and enhanced cultural controls (sanitation, proper fertilization and watering). Modern pest control strategies also include physical controls such as barrier screening.

Greenhouses are usually considered protected crop areas, but most are not sealed off from the outdoor environment so pests manage to enter through cooling fans, side and top intake vents, open sidewalls and so on. Sealing those areas with barrier screening will effectively prevent the movement of several pest insect species into the high-value crops. Although screening will not make the greenhouse insectproof, coupled with the use of insectfree plants, it will markedly reduce the need for pesticide applications.

In this study, we tested numerous screening materials, evaluating their effectiveness in keeping common pests out of greenhouses.

\section{Methods}

We examined a variety of barrier screens that could be used for excluding the adult stages of serpentine leaf miner, Liriomyza trifolii (Burgess); the green peach aphid, Myzus persicae (Sulzer); the melon aphid, Aphis gossypii Glover; the silverleaf whitefly, Bemisia argentifolii Bellows and
Perring; and the western flower thrips, Frankliniella occidentalis (Pergande). We also tested the screens to see whether any would allow the passage of the commercially produced parasitoid wasp of whiteflies, Encarsia formosa, while restricting whiteflies. If such a screen could be identified, growers could raise $E$. formosa on whiteflies within a screened enclosure, without the threat of releasing whiteflies into the entire greenhouse. The wasps, however, would be free to pass through the screened enclosure and attack whiteflies throughout the greenhouse.

Woven brass screens with a regular weave resulting in square holes from 0.037 to $0.880 \mathrm{~mm}^{2}$ (see photo above) were used as standards to investigate the relationship between hole size and ability to exclude pests. In addition to the standard woven brass screens, three other screen types were tested: high-density polyethylene sheets, high-density polyethylene or polyester fiber screens, and an unwoven polyester filter.

The high-density polyethylene sheets were an unwoven material with holes formed during the manufacturing process. The sheets had two very 


\begin{tabular}{|c|c|c|c|c|c|c|}
\hline Raw material & $\begin{array}{c}\text { Trade or } \\
\text { common name }\end{array}$ & Description & Supplier & Holes $/ \mathrm{cm}^{2}$ & $\begin{array}{c}\text { Hole shape and } \\
\text { dimension }\end{array}$ & Hole size \\
\hline & & & & & $\mu m$ & $\mathrm{~mm}^{2}$ \\
\hline Polyethylene sheet & Vispore $1600^{\circ}$ & $\begin{array}{l}\text { Holes formed } \\
\text { in plastic sheet }\end{array}$ & Tredegar & 248 & square $(270 \times 270)$ & 0.073 \\
\hline Polyethylene sheet & Vispore $400^{\circ}$ & $\begin{array}{l}\text { Holes formed } \\
\text { in plastic sheet }\end{array}$ & Tredegar & 62 & square $(337 \times 337)$ & 0.114 \\
\hline Polyethylene fiber & 50062280 & $\begin{array}{l}\text { Fibers woven into a 1:1 } \\
\text { regular weave screen }\end{array}$ & Lumite & 350 & square $(308 \times 308)$ & 0.095 \\
\hline Polyethylene fiber & 50060435 & $\begin{array}{l}\text { Fibers woven into a } 1: 1 \\
\text { regular weave screen }\end{array}$ & Lumite & 135 & square $(530 \times 530)$ & 0.281 \\
\hline Polyethylene fiber & 50094435 & $\begin{array}{l}\text { Fibers woven into a 2:1 } \\
\text { twill weave screen }\end{array}$ & Lumite & 240 & square $(340 \times 340)$ & 0.116 \\
\hline Polyethylene fiber & Anti-Virus Net & $1: 1$ regular weave & Green-Tek & 180 & rectangular $(239 \times 822)$ & 0.197 \\
\hline Polyester fiber & Bug bed 85 & $1: 1$ regular weave & Green Thumb Group & 1,024 & square $(200 \times 200)$ & 0.040 \\
\hline Polyester fiber & Bug bed 123 & $1: 1$ regular weave & Green Thumb Group & 2,304 & square $(135 \times 135)$ & 0.018 \\
\hline Polyethylene fiber & Econonet $\mathrm{L}$ & $1: 1$ regular weave & L. S. Americas & 121 & square $(659 \times 659)$ & 0.434 \\
\hline Polyethylene fiber & Econonet $\mathrm{T}$ & 1:1 regular weave & L. S. Americas & 527 & rectangular $(150 \times 450)$ & 0.068 \\
\hline Polyethylene fiber & No Thrip & $1: 1$ regular weave & Green-Tek & 1,089 & square $(134 \times 134)$ & 0.018 \\
\hline Metalized polyester fiber & Protex 1 & Warp-net knitted & Perifleur Products & 297 & $\begin{array}{l}\text { triangular (base } 267 \text {, } \\
\text { altitude } 738 \text { ) }\end{array}$ & 0.099 \\
\hline Polyester fiber & Protex 2 & Warp-net knitted & Perifleur Products & 473 & $\begin{array}{l}\text { triangular (base } 313 \text {, } \\
\text { altitude } 511 \text { ) }\end{array}$ & 0.080 \\
\hline Brass wire & 100-mesh screen & $1: 1$ regular weave & C. O. Jelliff & 1,552 & square $(192 \times 192)$ & 0.037 \\
\hline Brass wire & 60-mesh screen & $1: 1$ regular weave & C. O. Jellift & 557 & square $(462 \times 462)$ & 0.213 \\
\hline Brass wire & 50-mesh screen & $1: 1$ regular weave & C. O. Jellift & 388 & square $(537 \times 537)$ & 0.288 \\
\hline Brass wire & 40-mesh screen & $1: 1$ regular weave & C. O. Jelliff & 246 & square $(640 \times 640)$ & 0.410 \\
\hline Brass Wire & 30-mesh screen & $1: 1$ regular weave & C. O. Jelliff & 139 & square (938 x 938) & 0.880 \\
\hline Polyester fiber & Fly Barr & Dense unwoven filter & Hygro-Gardens & $n / a$ & $n / a$ & $n / a$ \\
\hline
\end{tabular}

different sides - male and female. The female side was smooth to the touch, with funnel-shaped holes appearing pushed through the sheet. The male side had distinct crown-shaped protrusions and felt rough to the touch. Because insects might respond differently to the surface characteristics of the male and female sides, each side was tested separately for its exclusion potential. The high-density polyethylene and polyester fiber screens had been manufactured using various regular and irregular weaves. For these fiber screens, the resulting hole size and shape (square, rectangular, triangular) varied according to the weave used during manufacturing. The unwoven polyester filter was simply polyester fibers pressed together to form a filter containing holes of various sizes.

The number of holes per $\mathrm{cm}^{2}$, the hole size, shape and dimension were determined microscopically with an ocular micrometer for all screen materials except the unwoven polyester filter, which was constructed much like a common furnace filter. Due to the variable thickness of the material and the variable hole sizes, the number of holes per $\mathrm{cm}^{2}$ could not be determined for the unwoven polyester filter (table 1).

To evaluate the exclusion characteristics of the four types of screen, insects of each species (except $E$. formosa wasps) were placed in replicate cages manufactured from the screen materials listed in table 1 . The cages were placed in environmental chambers with light, food (plant material) and water located outside of the cages. To reach the light, food or water, the insects had to penetrate the screen on the cage. We recorded the number of insects that were able to penetrate each type of screen in a 24-hour period.

In a separate experiment, brass screens with hole sizes of 0.037 and $0.213 \mathrm{~mm}^{2}$, polyethylene fiber screens with hole sizes of 0.095 and $0.116 \mathrm{~mm}^{2}$ and polyethylene sheet barriers with hole sizes of 0.073 and $0.114 \mathrm{~mm}^{2}$ (male and female sides facing the source of insects) were evaluated for their ability to prevent whitefly passage while allowing the passage of the parasitoid wasp, E. formosa. In this experiment, both whiteflies and wasps were simultaneously placed in cages and their ability to pass through the screens was determined as above.

\section{Results}

The hole sizes for the brass screens tested ranged from 0.037 to $0.880 \mathrm{~mm}^{2}$. Western flower thrips were able to pass through all the brass screens tested (fig. 1). Leaf miners were not able to pass through screens with hole sizes smaller than $0.410 \mathrm{~mm}^{2}$. Melon aphids and silverleaf whiteflies were not able to pass through screens with hole sizes smaller than $0.213 \mathrm{~mm}^{2}$. Green peach aphids were not able to pass through any of the brass screens tested (data not shown).

The hole sizes for the polyethylene and polyester fiber screens tested ranged from 0.018 to $0.434 \mathrm{~mm}^{2}$. As with the brass screens, western flower thrips were able to pass through all 
Brass screens

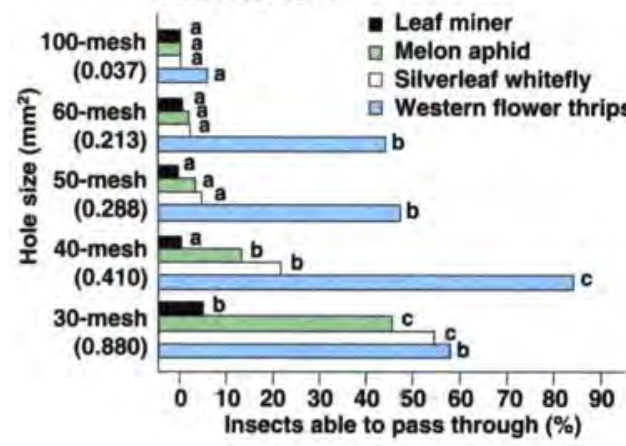

Fig. 1. Effectiveness of brass screens in preventing the movement of leaf miner, melon aphid, silverleaf whitefly and western flower thrips. For a particular insect, screens with the same letter are not significantly different from one another in their ability to exclude that insect $(p<0.05$ ANOVA and Ryan's multiple range $Q$-test). All the brass screens tested prevented passage of green peach aphids.

the fiber screens (fig. 2), while green peach aphids were unable to pass through any of them. However, the fiber screens also prevented the passage of leaf miners. In general, melon aphids and silverleaf whiteflies could pass through fiber screens with hole sizes of $0.281 \mathrm{~mm}^{2}$ or larger. Silverleaf whiteflies also could pass minimally through the Protex 2 material, which had smaller, $0.080 \mathrm{~mm}^{2}$, but triangular-shaped holes.

Only two polyethylene sheet screens were tested, with hole sizes of 0.073 and $0.114 \mathrm{~mm}^{2}$. Both the male and female side of each screen were tested. Western flower thrips were able to pass though any combination of hole size and surface - male or female - in the polyethylene sheet screens (fig. 3). However, these screens completely excluded green peach aphids and leaf miners, regardless of surface or hole size. Melon aphids and silverleaf whiteflies were marginally able to pass through them if the female side of the screen was facing the insects as they attempted to pass through. The male side of the screens was much more effective in reducing thrips movement (it did not eliminate movement, however) and completely stopped the movement of melon aphids and silverleaf whiteflies.

With the exception of green peach aphid, all the insects tested were able

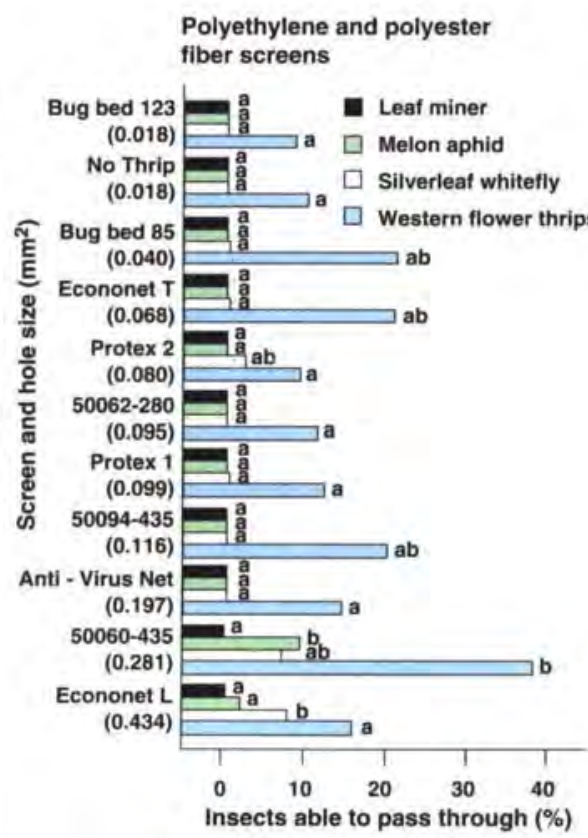

Fig. 2. Effectiveness of polyethylene and polyester fiber screens in preventing the movement of leaf miner, melon aphid, silverleaf whitefly and western flower thrips. For a particular insect, screens with the same letter are not significantly different from one another in their ability to exclude that insect $(p<0.05$ ANOVA and Ryan's multiple range Q-test). All the polyethylene and polyester fiber screens tested prevented passage of green peach aphids.

to pass easily though the unwoven polyester filter (data not shown).

Of the six materials tested for their ability to allow $E$. formosa parasitoid wasps, but not whiteflies, to pass through, only the polyethylene fiber (hole size $0.116 \mathrm{~mm}^{2}$ ) allowed the wasps to move through the screen in relatively significant numbers while

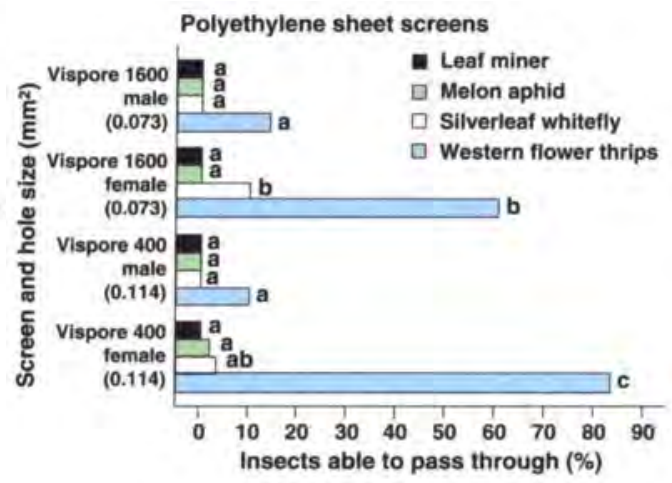

Fig. 3. Effectiveness of polyethylene sheet screens in preventing the movement of leaf miner, melon aphid, silverleaf whitefly and western flower thrips. For a particular insect screens with the same letter are not significantly different from one another in their ability to exclude that insect $(p<0.05$ ANOVA and Ryan's multiple range Q-test). All the polyethylene sheet screens tested prevented passage of green peach aphids. These screens are no longer being manufactured.

confining the whiteflies to the cage. The other materials tested either prevented the movement of $E$. formosa or allowed unacceptable numbers of silverleaf whitefly to pass (table 2).

\section{Conclusions}

Growers have a choice of many types of insect pest exclusion screens for greenhouses; we tested only a portion of them. Before selecting materials for screening greenhouses, growers need to consider the price of the material (including installation), the type and economic value of the crop being grown, the pests to be excluded and the effect the screening will have on greenhouse conditions.
TABLE 2. Effectiveness of screens tested to prevent passage of whitefly while allowing passage of parasitoid wasps

\begin{tabular}{|c|c|c|c|c|}
\hline Raw material & Description & Hole size & $\begin{array}{c}\text { Whiteflies } \\
\text { penetrating } \\
\text { screen }\end{array}$ & $\begin{array}{c}\text { Wasps } \\
\text { penetrating } \\
\text { screen }\end{array}$ \\
\hline & & $m m^{2}$ & $\%$ & $\%$ \\
\hline Polyethylene sheet & $\begin{array}{l}\text { Holes formed in plastic sheet; } \\
\text { male side toward insects }\end{array}$ & 0.073 & 0 & 0 \\
\hline Polyethylene sheet & $\begin{array}{l}\text { Holes formed in plastic sheet; } \\
\text { female side toward insects }\end{array}$ & 0.073 & 0 & 0 \\
\hline Polyethylene sheet & $\begin{array}{l}\text { Holes formed in plastic sheet; } \\
\text { male side toward insects }\end{array}$ & 0.114 & 5.6 & 1.3 \\
\hline Polyethylene sheet & $\begin{array}{l}\text { Holes formed in plastic sheet; } \\
\text { female side toward insects }\end{array}$ & 0.114 & 4.1 & 32.4 \\
\hline Polyethylene fiber & $1: 1$ regular weave & 0.095 & 0 & 6.5 \\
\hline Polyethylene fiber & 2:1 twill weave & 0.116 & 0 & 13.6 \\
\hline Brass wire & $1: 1$ regular weave & 0.037 & 0 & 0 \\
\hline Brass wire & $1: 1$ regular weave & 0.213 & 17.7 & 5.2 \\
\hline
\end{tabular}


Metal screens are quite durable, but are very costly; hence, they are rarely used. Polyethylene and polyester materials, although relatively inexpensive, may last only a relatively short time when exposed to sunlight and the outside environment; however, they are easily replaced. Whichever screen is considered, the costs should be balanced against the savings from reduced pesticide applications.

The pore or hole size of the material (rather than the holes per $\mathrm{cm}^{2}$ or strands per $\mathrm{cm}^{2}$ ) is the most important consideration in choosing a good screen. Most of the screens tested restricted insect movement to some extent (including the unwoven polyester filter), thus reducing overall pest pressure and providing some protection. Absolute exclusion of certain insect pests (for example, to prevent disease transmission) will require different screen characteristics depending on the insect to be excluded. Although most screens tested obstructed thrips to some extent, none completely excluded them. Green peach aphids and serpentine leaf miners can be excluded by materials with a rather large hole size (any hole smaller than about 0.880 $\mathrm{mm}^{2}$, fig. 1). Melon aphids and silverleaf whiteflies can be excluded with screens with a hole size of approximately $0.19 \mathrm{~mm}^{2}$ or less (fig. 2).

For the purposes of pest exclusion, the shape (square, rectangular or triangular) of the screen holes does not appear to significantly affect the effectiveness of the screen (table 1, figs. 1, 2 and 3). However, in newer materials such as Protex 2, which has triangular holes, hole shape may influence penetratability.
Screening may have a second use for greenhouse growers. By isolating a portion of infested host crop within a cage or section of the greenhouse, growers could have a nurse crop for the local production of biological control organisms. The screen would need to be able to confine the pest insect to the cage while allowing the biological control organism to pass through the screen and forage for pests in the greenhouse crop. In our study, using a polyethylene fiber screen (2:1 twill weave, $0.116 \mathrm{~mm}^{2}$ hole size), we were able to keep silverleaf whiteflies confined to a host plant within a screened cage while allowing the whitefly parasitoid, E. formosa, to pass through the screen (table 2).

The impact of screens on the greenhouse environment can be significant. Screens reduce airflow into and out of the greenhouse and may, depending on position, reduce light levels.

Screens must be kept clean to minimize these effects. If greenhouses are retrofitted with screens, modifications may be needed, such as enlarging or adjusting the vents, adding more vents or adding additional fans or cooling systems. Before installing screens, growers are strongly urged to consult their nearest horticultural farm advisor, an environmental engineer or their greenhouse manufacturer for information on how they may affect the greenhouse environment.

James A. Bethke, Richard A. Redak and Timothy D. Paine are Staff Research Associate, Assistant Professor and Associate Professor, respectively, in the Department of Entomology, UC Riverside.
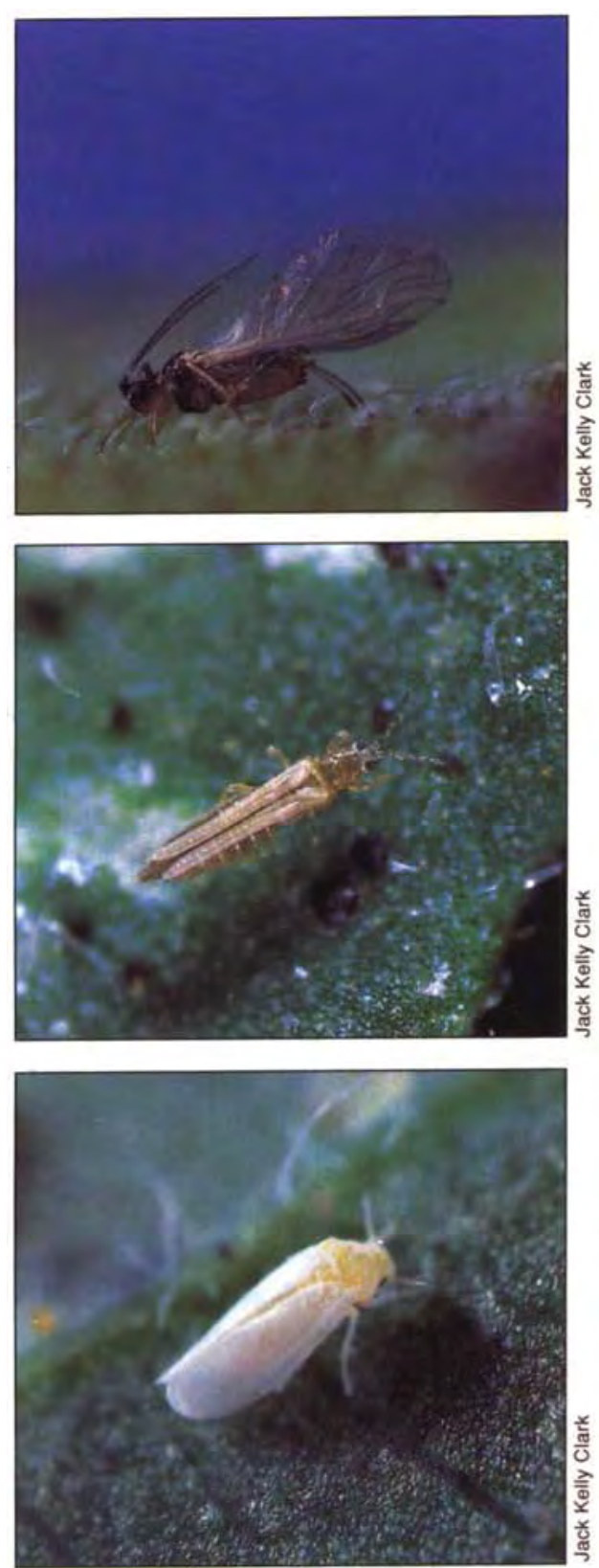

From top, adult green peach aphid, western flower thrip and silverleaf whitefly are among the pests that researchers attempted to exclude from greenhouses using barrier screening.

\section{CALIFORNIA AGRICULTURE ASSOCIATE EDITORS}

Animal, Avian, Aquaculture

and Veterinary Sclences

Richard H. McCapes

(2nd assoc. editor to be announced)

Economics and Public Pollcy

Harold O. Carte

Alvin Sokolow

Food and Nutrition

Barbara Schneeman

Eunice Williamson

Human and Community Development

Linda M. Manton

Karen P. Varcoe
Land, Alr \& Water Sclences

J. Brian Mudd

Garrison Sposito

Henry J. Vaux, Jr.

Natural Resources

Daniel W. Anderson

John Heims

Richard B. Standiford

Pest Management

Michael Rust

Frank Zalom

Plant Sclences

Calvin O. Qualset

G. Steven Sibbett

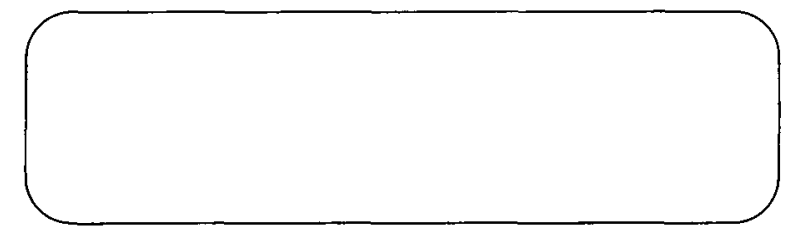

